\title{
Trends in abundance of marine fishery resources in India examined through dynamic factor analysis
}

\author{
T. V. SATHIANANDAN, SOMY KURIAKOSE, K. G. MINI, GRINSON GEORGE AND \\ P. U. ZACHARIA \\ ICAR-Central Marine Fisheries Research Institute, P. B. No. 1603, Kochi- 682 018, Kerala, India \\ e-mail: grinsongeorge@gmail.com
}

\begin{abstract}
Dynamic factor analysis (DFA) was used to identify common trends to explain the variability for a historical time series data (1980-2010) on all India annual marine fish landings for 16 resource groups. In this study, three common trends were identified for classifying the resource groups. Trend-1 increases gradually and reaches a peak in 1997, decreases sharply until 2001 and then increases further. Landings of carangids were clearly related to trend- 1 with positive factor loading magnitude. Trend-1 is important for Bombayduck as well but with negative factor loading. In the case of trend-2, it is declining until 1993 and remains steady with slight fluctuations till 2003 and increases further. Both, silverbellies and pomfrets landings were determined by trend- 2 with similar positive factor loadings. All other resources were associated with more than one trend. Trend-3 shows an increasing trend throughout the period with slight fluctuations. Perches, seerfishes, tunnies, flatfishes, crustaceans and molluscs formed a homogenous group associated with both trend- 1 and trend-3. These trends were important for elasmobranchs too as they had similar loadings on both trends but with opposite signs. Resource-wise explanations based on the different trends are discussed citing the examples of clupeids, carangids, Bombayduck, pomfrets and silverbellies.
\end{abstract}

Keywords: Common trends, Dynamic factor analysis, India, Marine fisheries, Time series

\section{Introduction}

Marine fishery resources often show fluctuations in their landings which could be attributed to variations in fishing efforts, temporal fluctuations in environmental variables and natural prey-predator cycles (FAO, 2011). Marine fishery resources harvested from the Indian EEZ reflects a typical tropical fishery with high species diversity (Sathianandan et al., 2011). More than 1200 species are landed by different categories of commercial fishing crafts in 1511 demarcated locations termed as landing centres spread along the $6100 \mathrm{~km}$ coastline in the main land of the country (CMFRI, 2012). The estimates of landings of different marine fish resource groups available in the database of the National Marine Fishery Resources Data Centre (NMFDC) of the ICAR-Central Marine Fisheries Research Institute (CMFRI), generated following a stratified multistage random sampling design (Srinath et al., 2005), formed the input for this study. The database provides information on species-wise marine fish landings for 75 nonoverlapping fishing zones covering the entire coast line of India, as well as information related to fishing crafts and gears used in the fishery.

In the year 1950, the marine fish harvest in India was about 0.5 million t only. Gradually, fishing emerged as a major commercial activity due to mechanisation of fishing crafts and gears with production level reaching 1 million t (Vivekanandan, 2006). Efficiency of fishing crafts and gears improved with technical sophistication during the period 1970-80 along with geometric growth in the number of fishing vessels after 1970. As a result, the marine fish landings reached near 2 million $t$ in 1980s (Sathianandan et al., 2011). Heavy investment in harvest and post-harvest sectors, expansion of fishing grounds and multi-day fishing voyages during the 1990s led to further exploitation of marine fishery resources with potential for export and as a result the marine fish landings in India reached a record 3.94 million $t$ in 2012 (CMFRI, 2013). The fishery developed over the years with steady increase in marine fish landings. During this time research and policy related questions were debated on the sustainability of stocks of some or more of the fish species in the Indian EEZ (Sathianandan et al., 2011). For a policy planner, it is essential to identify the trends in landing pattern so as to develop suitable recommendations for the assessment and management of the fishery. There are few dominant species which contribute mainly to the marine fishery in the EEZ of India (CMFRI, 2013). These species show lot of inter annual variability in their landings. 
In the ecosystem perspective, few resources may share or contribute significantly to a common trend when examined together as a multivariate time series. Dynamic factor analysis (DFA) is a statistical tool used to identify and extract common trends existing in multivariate time series data and it can be used to estimate common trends in short and non-stationary time series (Zuur et al., 2003; Zuur and Pierce, 2004). Globally there were several attempts to model trends in marine fishery resources with the help of DFA (Zuur et al., 2003; Zuur and Pierce, 2004; Chen et al., 2006; Huang et al., 2006). In this study recent historic data were analysed to delineate the common trends for major fishery resources landed along the Indian coast. The different resource groups were examined separately to see the reasons for the trend patterns. The study made a distinction between the term 'resources' and 'stocks'. While the paper identifies common trends of fish 'resources' landed in India, the resources are harvested from multiple fish 'stocks'. So the common trends identified in this study are not indicative of the abundance of any specific fish stock but help to identify which fish resources need priority in terms of monitoring, assessment and management for sustainable fisheries in India.

\section{Materials and methods}

ICAR-Central Marine Fisheries Research Institute has developed a sampling design for collection, classification and estimation of marine fish landings along with the fishing effort expended (Sathianandan et al., 2011). The data used in this study, spanning across the 31 year period from 1980 to 2010 , comprises of time series on annual all India landings of 16 marine fishery resource groups including finfishes, crustaceans and molluscs. The fishery in India up to 1980 was mostly traditional, with minimal fishing pressure on the resources. Mechanisation, motorisation and development of more efficient fishing gears intensified after 1980 and hence the trends during the periods before and after 1980 are not comparable. The commercial requirement in terms of quantity of fish landed formed the major criterion for selection of the 16 important resource groups, because these resources are targeted species and thus, looking at their trends alone would provide sufficient information to prioritise fisheries assessment and management in India. The resource groups with more than $1 \%$ average contribution $(39,000 \mathrm{t}$ in terms of quantity) towards total landings were selected for inclusion in the model and together they account for more than $90 \%$ of the total annual landings in the country. The timeseries vectors are usually standardised before subjecting them to DFA. However in this study, all the time series vectors used were in the same scale (or units) and hence this step does not affect the results (Zuur et al., 2003).
Dynamic factor analysis

The general model underlying DFA (Zuur et al., 2003) is: $Y_{t}=A Z_{t}+B x_{t}+\varepsilon_{t}$

where,

$Y_{t}=\left(Y_{l t}, \ldots, Y_{k}\right)^{\prime}$ is a time series vector of $\mathrm{k}$ response variables

$Z_{t}=\left(Z_{l t}, \ldots, Z_{t m}\right)$ ' is a vector of $\mathrm{m}$ common trends $(\mathrm{m}<\mathrm{k})$

$x_{t}=\left(x_{l t}, \ldots, x_{p}\right)^{\prime}$ is a time series vector of $\mathrm{p}$ explanatory variables

$A=\left(a_{i j}\right)_{k x m}$ is a parameter matrix of order $k \times m$

$B=\left(b_{i j}\right)_{k x p}$ is a parameter matrix of order $k \times 1 p$ and

$\varepsilon_{t}=\left(\varepsilon_{l l}, \ldots, \varepsilon_{k}\right)^{\prime}$ is the time series vector of k error terms that are assumed to be distributed with zero mean vector and a symmetric dispersion matrix $\sum$.

The time series of landed catch for each resources forms the response variable of the model. In the present study, as we are not considering any explanatory time series variables for modeling, the DFA version without explanatory variable term $\left(B x_{t}\right)$ in the model was used. The DFA technique resembles a factor analysis in the sense that new factors are created, although may be fewer in number than the original variables, that are expected to explain most of the variation (Azevedo et al., 2008). In the present study, DFA is resorted to set ' $m$ ', the number of common trends, as small as possible but still have a reasonable model fit. The decision on the number of common trends in the data was made using Akaike Information Criterion (AIC). In general, AIC is computed as $2(r-\log \mathrm{L})$, where $r$ is the number of parameters in the model, and $L$ is the maximised value of the likelihood function for the estimated model (Akaike, 1974). As per this, the model yielding the smallest AIC value was selected as the appropriate one. The relationship between response variables and the common trends were assessed using the values of factor loadings. The time series data was scaled for unit variance by dividing annual values by the standard deviation of the series to facilitate the interpretation of factor loadings. The necessary computations were carried out using Brodgar computer software, developed by Highland Statistics Ltd., UK (www.brodgar.com).

\section{Results and discussion}

A series of DFA models were fitted for the scaled time series of annual landings of the 16 resources for a range between one and four common trends. The model containing three common trends was found as the best model based on the smallest AIC value (Table 1).

Table 1. Model selection based on AIC value

\begin{tabular}{lcccc}
\hline $\begin{array}{l}\text { Number of } \\
\text { common trends }\end{array}$ & 1 & 2 & 3 & 4 \\
\hline AIC values & 1088.426 & 1059.251 & 1054.768 & 1068.206 \\
\hline
\end{tabular}


The observed values and the fitted model for the time series data were categorised, based on the $\mathrm{R}^{2}$ value generated during the study, as very good $\left(R^{2} \geq 0.8\right)$, good $\left(0.8>R^{2} \geq 0.7\right)$, moderate $\left(0.7>R^{2} \geq 0.5\right)$, low $\left(0.5>R^{2} \geq 0.2\right)$ and very poor $\left(R^{2}<0.2\right)$. The threshold used for these categories were arbitrary values to facilitate qualitative comparisons. The study showed very good model fit for clupeids, perches, carangids, tunnies, crustaceans and molluscs (Table 2). The fit was good in the case of catfish and ribbonfish and it was moderate for mackerel, seerfish and flatfish. On the other hand, the individual model fit was low for elasmobranchs, croakers, silverbellies, pomfrets and very poor for Bombayduck. until 1993, remains steady with slight fluctuations till 2003 and increases sharply till the end of the data series. The third trend shows an increasing trend throughout the period, with slight fluctuations.

The factor loadings indicate the relationship between common trend and the resource group series. A Venn diagram is used to show all possible relationships between the resource groups considering only those factor loadings with absolute value more than 0.1 (Fig. 2). While 0.2 is commonly used as the cut-off point, here this was relaxed to 0.1 (Zuur et al., 2003). Carangids contribute towards trend- 1 only with a factor loading of 0.288 . Both silverbellies and pomfrets contribute only towards trend-2,

Table 2. Factor loadings for the three common trends, residual variance and measure of fit (threshold taken as 0.1 ) for individual models yielded by DFA

\begin{tabular}{|c|c|c|c|c|c|c|}
\hline \multirow{2}{*}{$\begin{array}{l}\text { Resource } \\
\text { group }\end{array}$} & \multicolumn{3}{|c|}{ Factor loadings for common trends } & \multirow{2}{*}{$\begin{array}{l}\text { Residual } \\
\text { variance }\end{array}$} & \multirow{2}{*}{$\begin{array}{l}\text { Measure of } \\
\text { fit }\left(R^{2}\right)\end{array}$} & \multirow{2}{*}{ Fit } \\
\hline & Trend-1 & Trend-2 & Trend-3 & & & \\
\hline Elasmobranchs & 0.158 & -0.015 & -0.164 & 0.558 & 0.442 & Low \\
\hline Catfishes & 0.005 & 0.343 & 0.126 & 0.255 & 0.745 & Good \\
\hline Clupeids & 0.050 & 0.118 & 0.264 & 0.103 & 0.897 & Very good \\
\hline Bombayduck & -0.122 & -0.097 & 0.097 & 0.959 & 0.041 & Very poor \\
\hline Perches & 0.137 & -0.030 & 0.259 & 0.071 & 0.929 & Very good \\
\hline Croakers & 0.312 & 0.171 & 0.056 & 0.510 & 0.490 & Low \\
\hline Ribbonfishes & 0.038 & -0.143 & 0.251 & 0.277 & 0.723 & Good \\
\hline Carangids & 0.288 & -0.009 & 0.098 & 0.182 & 0.818 & Very good \\
\hline Silverbellies & 0.076 & 0.367 & -0.094 & 0.687 & 0.313 & Low \\
\hline Pomfrets & 0.078 & 0.399 & -0.010 & 0.599 & 0.401 & Low \\
\hline Mackerel & 0.358 & 0.153 & 0.009 & 0.384 & 0.616 & Moderate \\
\hline Seerfishes & 0.100 & -0.015 & 0.226 & 0.334 & 0.666 & Moderate \\
\hline Tunnies & 0.135 & -0.007 & 0.240 & 0.181 & 0.819 & Very good \\
\hline Flatfishes & 0.205 & -0.067 & 0.105 & 0.483 & 0.517 & Moderate \\
\hline Crustaceans & 0.261 & 0.010 & 0.168 & 0.155 & 0.845 & Very good \\
\hline Molluscs & 0.222 & 0.034 & 0.201 & 0.130 & 0.870 & Very good \\
\hline
\end{tabular}

The residual variance obtained after fitting the DFA model for each of the resource group are given in Table 2 along with factor loadings for the three common trends estimated and a measure of fit. The first common trend (Fig. 1) increases gradually, reaches a peak in 1997, decreases sharply until 2001 and then increases subsequently. The second trend shows a declining trend

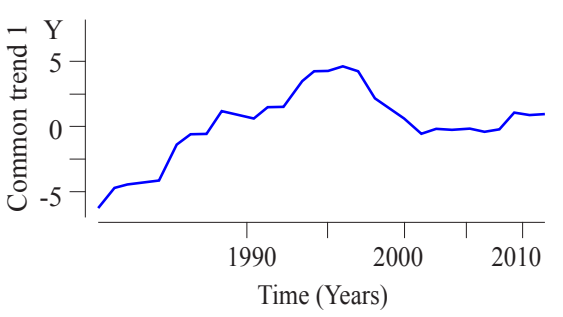

(a)

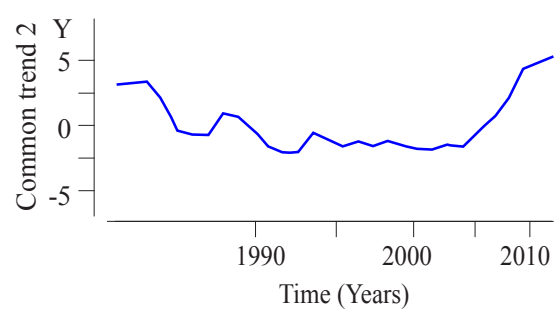

(b) both with positive and almost equal factor loadings of 0.367 and 0.399 respectively. Croakers and mackerel contribute almost equally towards trend- 1 and trend-2 whereas perches, seerfish, tunnies, flatfishes, crustaceans and molluscs form a homogenous group contributing almost equally towards trend-1 and trend-3. Clupeids and catfishes contribute towards trend- 2 and trend- 3 with both positive factor loadings.

Fig. 1. Common trends in landings of major marine fishery resource groups estimated using dynamic factor analysis

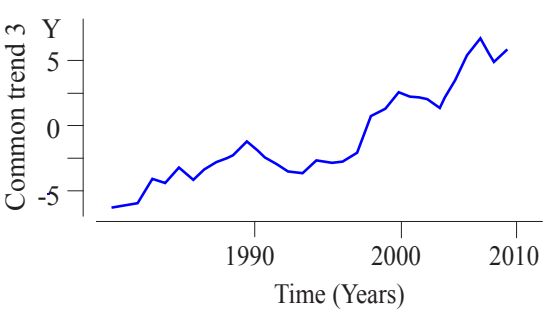

(c) 


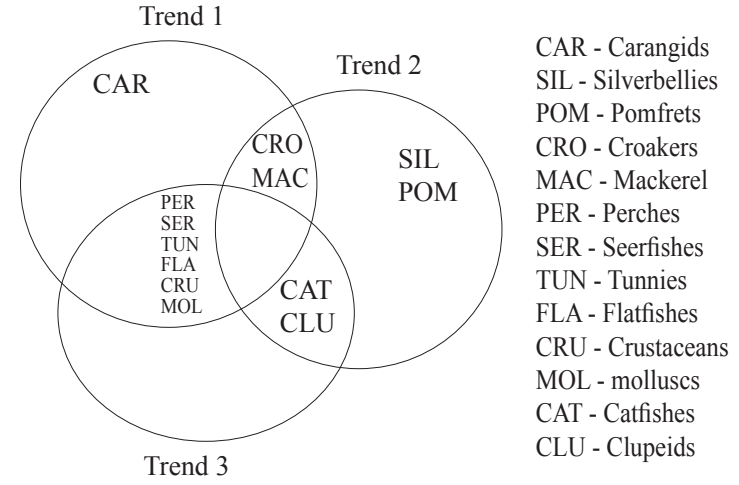

Fig. 2. Venn diagram representing common resource groups and corresponding trends

Three of the sixteen resource groups examined through DFA, namely carangids, silverbellies and pomfrets, contribute to only one of the three common trends, indicating that their dynamic behaviour over years is exclusively explained by the respective common trends individually. But the individual models fitted through DFA is very good only for carangids whereas it is low for silverbellies and pomfrets. Thus, the dynamics in landings of carangids is well explained by common trend-1 (Fig. 2). From the behaviour of these common trends it can be inferred that trends in landings of carangids is almost steady from 2001 onwards and have shown slight improvement in recent years. Though the factor loadings of clupeids and catfishes towards trend- 2 and trend- 3 are positive, their weightage is not uniform. Clupeids contribute more towards trend-3 whereas catfish contribute more towards trend-2. Thus the behaviour in landings of these two resources are slightly different. In a study carried out by Sathianandan et al. (2011), the status of clupeids and carangids was assessed as abundant through a rapid fish stock assessment. This is in corroboration with the inference in the present study.

In the cluster of six resources consisting of perches, seerfishes, tunnies, flatfishes, crustaceans and molluscs with almost equal contributions towards trend-1 and trend-3 (Fig. 2) it can be seen that all these resources except seerfishes and flatfishes have very good fit for their individual models, leading to the conclusion that these four resources have similar behaviour in their landings (Table 2). Croakers and mackerel form a separate group contributing equally towards common trends 1 and 2 . Both these resources feed on plankton but the individual models obtained through DFA are not good enough to explain their dynamic behaviour as a modulation of these two common trends.

DFA unravels the common patterns in landings to evaluate their trend independent of environmental variables. The possible reasons for the behaviour of the trend exhibited by a particular species and its fishery may be interpreted with the help of environmental variables if there is a similar environmental time series data set to support the study. The common trends in this study indicate a collective behaviour from multiple stocks and ecosystems. It is important to track the common trends in each stock or ecosystem individually to fully understand the behavioural dynamics of landed catch and subsequently, the population abundance. A typical example is the case of clupeids, where the environmental variables result in inter-annual fluctuations but the resource indicates a steadily increasing mixed response trend with fluctuations (trends 2 and 3 ) in the DFA model, reflecting the strength of this resource as reported in earlier studies (Sathianandan et al., 2011).

As per the Venn diagram, carangids contribute to trend-1 only and from DFA we get the individual models for these resource group as given below. The trend in landings of carangids is exactly similar to that of trend-1 scaled by the coefficient 0.288 . In a similar fashion, we can see that the trend in landings of clupeids is that of trend- 3 scaled by 0.264 .

$Y_{8 t}=0.288 Z_{1 t}-0.009 Z_{2 t}+0.098 Z_{3 t}+\varepsilon_{8 t}$ for carangids

Among the six resource groups with positive factor loading corresponding to trend-1 and trend-3, only perches, tunnies, crustaceans and mollucs have very good model fits. The proportion of factor loadings of perches and tunnies for both trend- 1 and trend- 2 are almost equal and hence they follow exactly similar behaviour in their landings, which is obtained by adding both trend-1 and trend-3 with the factor loadings as proper weights. Both trend- 1 and trend-3 initially increase but subsequently trend-1 decreases and trend-3 increases. As a result, the trend in landings of these two resources is an initial increase and then becoming almost stabilised later. Trend-1, trend-3 and landings of perches and tunnies are depicted in Fig. 3 and 4 respectively.

The biology and ecosystem complexities involved in these species are different and therefore DFA analysis indicate that trend- 1 is the best model for explaining

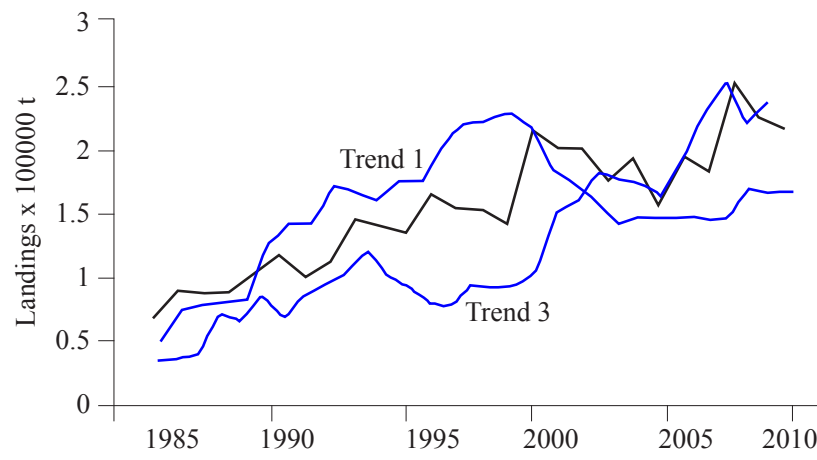

Fig. 3. Common trends 1 and 3 along with landings of perches 


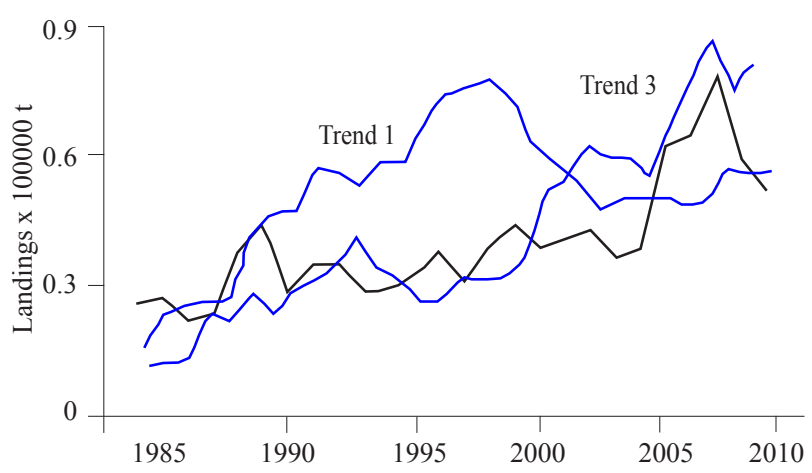

Fig. 4. Common trends 1 and 3 along with landings of tunnies

the trend in landings of carangids. On the contrary, silverbellies and pomfrets do not exhibit any prey-predator relationship. They have similar feeding habits and common prey, but occupy different ecological niches in the coastal water column. Therefore, the trends shown by silverbellies and pomfrets are independent of each other. All the other groups show mixed trends.

It is evident that the empirical indicators summarise trends in relation to fishing and environmental variability. But many of the indicators do not describe the effects on individual species. Response of a species to exploitation is mainly determined by its life history and events which affect the life history over time. The effects of fishing and environmental influences cannot be easily evaluated by aggregate indices which are skewed to environmental perturbations. DFA can also estimate index functions to evaluate interactions between explanatory variables which can repeatedly occur at regular intervals in a timeseries scale such as fishing effort, upwelling index and North Atlantic Oscillation (NAO) index. Environmental variables can also be used in DFA as explanatory variables if such data are available.

All the three trends identified in DFA during this study show an increase in the last decade, which may probably be because of more fishing effort rather than the overall abundance of the fish population. Another reason could be that higher landings from a single fish stock may mask the lower landings from other fish stocks of the same species. In a diverse tropical marine environment, excess landings of a particular species may affect some other related species. This is very common in the case of fishes which show prey-predator relationship. Hence, although the trends are indications of an existing pattern of fishing, a more holistic analysis is required for proper fisheries management.

\section{Acknowledgements}

The authors wish to thank the Director, ICAR-CMFRI, Kochi for providing necessary facilities for the conduct of this study. We also thank all the technical staff who were involved in the collection and processing of marine fish landings data from all along the Indian coast.

\section{References}

Akaike, H. 1974. A new look at the statistical model identification. Automatic Control, IEEE Transactions on Automatic Control, 19(6): 716-723.

Azevedo, M., Duarte R., Cardador, F., Sousa, P., Farina, C., Sanpedro, P., Landa, J. and Costas, G. 2008. Application of dynamic factor analysis in the assessment of Iberian anglerfish stocks. ICES J. Mar. Sci., 65: 1362-1369.

Chen, C. S., Bailey, N., Beare, D. J., Jereb, P., Mannini, A., Orsi-Relini, L., Pereira, J., Pierce, G. J., Poulard, J. C., Boyle, P. R., Ragonese, S., Robin, J. P.,Wang, J. and Zuur, A. F. 2006. The apparent disappearance of Loligo forbesi from the south of its range in the 1990s: Trends in Loligo spp. abundance in the north-east Atlantic and possible environmental influences. Fish. Res., 78: 44-54.

CMFRI 2012. Marine fisheries census 2010 Part I India. ICAR-Central Marine Fisheries Research Institute, Kochi, 98 pp.

CMFRI 2013. Annual Report 2012-13. ICAR-Central Marine Fisheries Research Institute, Kochi, 200 pp.

FAO 2011. Review of the state of world marine fishery resources. FAO Fisheries and aquaculture technical paper, No. 569. Rome, $334 \mathrm{pp}$.

Huang, J. J., Tzeng, G. H. and Ong, C. S. 2006. A novel algorithm for dynamic factor analysis. Applied mathematics and computation, 175: 1288-1297.

Sathianandan, T. V., Jayasankar, J., Somy Kuriakose, Mini, K. G. and Wilson T. Mathew 2011. Indian marine fishery resources: optimistic present, challenging future. Indian $J$. Fish., 58(4): 1-15.

Srinath, M., Kuriakose, S. and Mini, K. G. 2005. Methodology for estimation of marine fish landings in India. CMFRI Special publication No. 86, ICAR-Central Marine Fisheries Research Institute, Kochi, 57 pp.

Vivekanandan, E. 2006. Oceanic and deep-sea fisheries of India. In: Handbook of fisheries and aquaculture. Indian Council of Agricultural Research, New Delhi, p. 93-105.

Zuur, A. F. and Pierce, G. J. 2004. Common trends in north-east Atlantic squid time series. J. Sea Res., 52: 57-72.

Zuur, A. F., Truck, I. D. and Bailey, N. 2003. Dynamic factor analysis to estimate common trends in fisheries time series. Can. J. Fish. Aquat. Sci., 60: 542-552. 